\title{
An ethical dilemma in trauma care: A case presentation
}

\author{
Julie M Budinger ${ }^{1}$, Lewis L Mary ${ }^{2}$, Emmett K Mary ${ }^{3}$ \\ 1. Charleston Area Medical Center General Hospital, Trauma Services, Charleston, United States. 2. Clinical Ethicist and \\ Palliative Care Physician, Charleston Area Medical Center, Medical Affairs, Charleston, United States. 3. Director of Health \\ Services and Outcomes Research, Charleston Area Medical Center, Charleston, United States.
}

Correspondence: Julie M Budinger. Address: Charleston Area Medical Center General Hospital, Trauma Services, Charleston, United States. Email: julie.budinger@camc.org

Received: August 2, 2013

Accepted: September 17, 2013 Online Published: December 9, 2013

DOI : 10.5430/jnep.v4n2p171

URL: http://dx.doi.org/10.5430/jnep.v4n2p171

\begin{abstract}
A myriad of ethical challenges are present in this case study. A middle-aged man was admitted to a level I trauma-center in a large tertiary teaching hospital with multiple complicated severe injuries from a single motor vehicle accident. His identity was never accurately established and his wishes for his care were never elucidated. The ethical dilemmas and lessons learned are highlighted and discussed. The purpose for analyzing this experience is to understand the dynamics of the care given and to assist clinicians in the future with management of ethical issues in the care of difficult and disruptive patients.
\end{abstract}

\section{Key words}

Ethics, Trauma, Disruptive patients

\section{Introduction}

"This is one of the meanest people I have ever met.” "He will not cooperate. I really don't care what happens to him.” "How does he expect to get better if he doesn't even let us do anything?" "I don't even want to go in the room, but I would sure hate to miss something." These are actual statements of healthcare providers who cared for a difficult patient whom we will call Mr. D.

To what extent is, a competent patient expected to participate in his care? Was the treatment team misled by the patient concerning his capacity to make decisions about his health care? To what extent is the hospital responsible or liable to provide care to a competent yet uncooperative patient once acute medical issues are resolved? Did his behavior and uncooperativeness contribute to the clinical apathy and malaise of his caregivers and ultimately lead to his clinical deterioration? Was nursing care/surveillance suboptimal due to avoidance behaviors in this difficult and at times belligerent and cursing patient? The physician and nursing caregivers struggled throughout this patient's hospital stay with these questions. As Mr. D’s hospital length of stay increased, so did his healthcare providers frustrations alternating with apathy toward his recovery and overall disposition. Complications arising from patient-provider relationships prompted this ethical analysis. This case involves a complex patient illustrating medical and psychosocial issues, which were fluid over time. 


\section{Case presentation}

Mr. D was a 57 year-old man involved in a motor vehicle crash as an unrestrained driver. He sustained multiple injuries: left pneumothorax, concussion, and multiple fractures including nasal, pelvis, left rib and lumbar spine fractures complicated by alcohol intoxication (blood alcohol level $229 \mathrm{mg} / \mathrm{dl}$ ). Past medical and surgical history were significant for splenectomy.

\section{I nitial phase}

He was admitted to the surgical trauma ICU for observation and quickly transferred to a less intense level of care. Capacity to make medical decisions was presumed to be intact. The first left chest tube was placed and removal planned when output decreased. As with all hospitalized patients, discharge plans were initiated. Mr. D, however, refused to participate in physical therapy and get out of bed. Furthermore, when asked about discharge time and destination he stated he would leave "when I please". He was not engaged. A reasonable conversation with the patient was impossible because of his incessant foul language, belligerent demands, and inconsistent responses. He was repugnant to the staff's sensitivities. He was distasteful and objectionable in his relationship with his attending physicians and nurses.

Initial social history included being allegedly from Texas en route to Baltimore, which later was changed to being a local resident. Further history as given by Mr. D was that he was a widower without children or siblings. His parents were deceased and he appeared to be alienated from all members of his family. He stated he was retired but had worked intermittently as a "boat captain”. He stated he belonged to the Christian Science faith but because of the inconsistency in his history, we suspected he was withholding or fabricating information about his past.

\section{Complicated phase}

On hospital day seven, a chest X-Ray was suspicious for loculated hematoma confirmed in a chest CAT (Computerized Axial Tomography) scan as evidence of retained hemothorax with probable empyema. A second chest tube was recommended. While discussing the risks and benefits with the patient, he adamantly refused, "I don't need it and just give me another 48 hrs to resolve the problem.” From a functional standpoint, he was ambulating with moderate assistance. He was making progress.

However, the surgeon explained to Mr. D that delay would increase the need for open chest surgery as well as increase the risk for sepsis, respiratory and renal failure, heart attack and death. Again, the patient refused from lack of either understanding or obstinance. The physician suspected lack of capacity in decision-making and consulted Behavioural Medicine for evaluation. The psychiatrist's initial evaluation revealed an angry patient without family or friends. Discussion revealed the patient did not have the capacity to understand the gravity of his current medical situation.

Meanwhile, his condition deteriorated and he was emergently transferred to the Intensive Care Unit (ICU) necessitating life-saving procedures. These procedures included intubation, bilateral chest tube placements, drainage of left chest wall abscess and left thoracotomy to evacuate the hematoma. The sepsis resulted in adult respiratory distress syndrome (ARDS), gastrointestinal bleeding, delirium, acute onset atrial fibrillation, acute renal failure requiring dialysis, tracheostomy for respiratory failure and prolonged mechanical ventilator support. His overall prognosis was guarded. While he was fighting for his life, the social worker referred the patient to the Department of Health and Human Resources (DHHR) who refused to be the surrogate decision maker because Mr. D was believed to be from another state. The patient had no advanced directives and no surrogate.

The ethics committee was consulted due to an inability to determine a surrogate decision-maker. They discovered that Mr. D was driving without a valid driver's license and the provided ID was false. Even though the police would not do finger printing, an action plan was devised by the hospital to contact the FBI for fingerprint identification. The patient's survival was the only criteria for decision-making due to the patient's incapacity. Implied consent was ethically and legally appropriate since it was necessary to proceed with all medically advised treatment for his survival, while continuing efforts to locate an appropriate surrogate ${ }^{[1]}$. 
Attempts to determine the patient's identity were thorough. Both the Medicare number and a valid address turned out to be spurious. It was a business address where no one had ever heard of Mr. D. When Mr. D had capacity, he refused to provide a county of birth or the name of his mother for a valid birth certificate or social security number. When he responded to repeated questions about obtaining Medicare and Medicaid, he calmly replied that "I do not need financial help because the hospitals will write-off my bill.” At one point, a person was identified as Mr. D’s cousin, who mysteriously called to check on the patient's status. The caller described him as a 'loner' and a 'drifter' who travelled the country. He was unaware of any permanent address; that his only close family, his mother, had died 6 years ago; and that he had never held a permanent job. Further, Mr. D was described as distrustful of authority and the cousin declined to act as health care surrogate.

At this point, the treating team continued using the "implied consent standard" for decision-making. Physicians made procedural decisions for the patient based on their medical knowledge to save his life. "Physicians may presume consent when immediate action is necessary to preserve the patient's life.” Otherwise, procedures would be considered assault and battery ${ }^{[1]}$.

\section{Recovery phase}

Once Mr. D survived the multiple life-threatening complications, tubes were removed and mechanical ventilator support was weaned, he returned to a stable level of care. Treatment goals were focused on rehabilitation and restorative function. Convalescing, he once again became belligerent, uncooperative and abusive to the treating staff.

Behavioral Medicine was consulted again regarding Mr. D’s recurrent uncooperative behaviour. The impression was that this was not paranoia, but rather withholding information voluntarily for secondary gain. His acting out behaviour was exhibited in an effort to gain control and attention consistent with a long-term abnormal personality pattern. The group recommended clear and consistent pain treatment schedules and prescribed an antipsychotic at bedtime. It was clear from their evaluation that the patient had regained decision-making capacity but refused to participate in any decisions concerning his care and discharge planning process. Despite their recommendations, his behaviour and verbal abuse continued unchanged with refusal to participate in physical therapy or even to get out of bed. Even bargaining, using pain medication as an incentive, did not affect his outward apathy. The patient had little desire to leave the hospital commenting, "I will walk out when I am ready." He assumed no responsibility for himself or his actions. Something had to be done from the team's viewpoint.

Through case management, a decision was made through corporate channels, authorizing payment to a skilled level of nursing care for reconditioning and strengthening. The patient declined the offer. A discharge date was set and the patient informed. The caring team believed this was his best option.

On the designated day of discharge, the patient was given his belongings, $\$ 1300$ in personal funds, clothing, a list of men’s homeless shelters, free clinics, food pantries and a wheelchair for mobile support. His destination is still unknown. In addition, since then, we have never heard from him.

\section{Discussion}

\section{Lessons learned}

\section{Disruptive patients do have rights}

Health care providers have a duty or fiduciary responsibility to administer appropriate care at the appropriate time ${ }^{[2]}$. Thus, care should be rendered regardless of one's likes or dislikes. 
Because of the enormous time utilization associated with disruptive patients, other patients do suffer. Mr. D required more one on one time than most comparable patients did. Because of this burden, caregivers would trade assignments rather than care for him. Therefore, continuity of care suffered. It was only because of the stubborn determination of the nurses that this patient recovered.

In caring for difficult patients, providers must be cognizant of their own feelings and natural tendency to avoid contentious behaviours. Reactions to disruptive patients vary. Some become the disapproving parent with a misbehaving child. For example, a doctor would lecture Mr. D for foul language. However, this chiding changed nothing. He simply did not use the forbidden language when the doctor was present. The team chose a beneficent paternalistic approach as a necessary mechanism to render care. This is ethically justified when the patient's behaviour otherwise prevents life saving procedures $^{[1]}$.

\section{I mmediate accurate assessment of decision-making capacity is essential to patient care}

Formal assessment of Mr. D’s decision-making capacity was not documented on admission, but presumed. It was a month before his lack of capacity was established by Behavioral Medicine. This assessment should have been done earlier and often. His behaviour generated increasing anger, as he was perceived to be nasty and foul as opposed to being ill and incapacitated. No one noticed when he regained capacity after the long ICU stay because his disruptive behaviours did not outwardly change. Ever-rotating caregivers compounded the problem.

Efforts persisted throughout his stay to establish an appropriate surrogate decision-maker. Because of this failure, decisions were made throughout on an implied consent standard. However, attention to this standard allowed the staff to ignore their conflicts, anger and repulsion by caring for him anyway. The manner of his discharge could be construed as an expression of their angst. Discharging him to the street in a wheelchair without leg supports appears to be a way of getting revenge. The staff may have wanted him to feel some of the anguish they had felt while he was in their care. A better way was to discharge him to the men's shelter by cab. Discharge to the street could be misconstrued as either abandonment or negligence.

\section{In optimal healthcare settings a dedicated multidisciplinary team could coordinate and address complex patient care issues}

This Team could include regularly scheduled visits from psychiatric and ethics services. A team approach could proactively identify problems and plan for resolutions earlier than occurred with Mr. D. A proactive rather than reactive approach would be more efficacious in mitigating conflicting feelings of knowing what is ethically appropriate and yet being unable to act on that knowledge because of barriers inherent in a situation. Both the patient and the team would benefit from such a dedicated effort.

For example, provision of a clear and consistent treatment plan especially for pain control would have thwarted Mr. D's ability to manipulate therapy and dosing of pain medications. He easily played nurses against each other in requesting pain medication. During this confusing sequence of events, continuity of care was essential and timely debriefing sessions would have blunted bitterness voiced by those caring for him. The conflict produced by his behaviour begged for solutions.

\section{Every patient deserves a spokesperson as needed}

Patients have the right for someone to speak for him or her. If the patient's preferences are not known or unknowable, the clinicians are obligated to provide care ${ }^{[3]}$.

Because of the ever-persistent differential in power between caregiver and patient, the team usually knows more about the patient's situation than the patient does. This chasm occurs regardless of the level of health literacy. Healthcare providers have ready computer access to information and therefore, have an upper edge on knowledge. Since knowledge is power, 
the medically naïve or perceptive patient is at a disadvantage. This lopsided knowledge base or paradigm is paternalistic at best and at worse can lead to abuse or combination of both. Patients may decide to "keep peace" with healthcare providers rather than chance crossing them even though the decision is not very consistent with their personal goals or best interest. At some level, they must trust medical skills, which they need for their own care or the care of a loved one. Sometimes patients hope for secondary gain such as early discharge or a favor and as in Mr. D’s case, more pain medication and continued hospitalization.

Healthcare providers may intercede and offer their preferred options before the patient has been able to process all the information. The incapacitated adult or child must have even more committed representation from a concerned other or parents throughout the hospital course. Family members usually fill this role, but at times, they are unable to be physically present, available or may even be nonexistent as with Mr. D. Other persons capable of fulfilling this surrogate role are friends, paid sitters from an established nursing service or court appointed guardian ad litem ${ }^{[4]}$. This legal term means "for the purposes of this legal action only”. The guardianship approach would terminate at the end of the event. This latter option would have been reasonable for Mr. D.

\section{All clinicians need to be knowledgeable of the determinants of decision-making capacity}

Caregivers should use this skill in the daily practice of caring for sick patients. The components are comprehension, evaluation, communication and deliberation. Without some type of evaluation and response, the administering of even an Aspirin or simple procedure, such as taking vital signs, could be construed as assault. For example, the patient must comprehend that the caregiver is interested in their welfare by the inflection of their voice, facial expressions and posture as well as their words or actions. The patient evaluates the caregivers request to take vital signs and then communicates back their consent to the procedure. Thus, they deliberate and comprehend the request to be in their best interest and they consent freely without coercion.

\section{In clinical encounter the caregiver must assess accurately multiple facets of the presenting circumstances}

The admitting team must collect and understand the medical findings, the patient's preferences, the quality of life as perceived by the patient and the contextual situation ${ }^{[1]}$. Clinicians cannot wait for an ethics consultant to analyze these factors for them. The clinician must accurately access both where the patient has been in their process and where they will go along the natural history of their affliction. Clinicians appear to be unaware of this continuous subliminal evaluation and many may take their perceptions for granted without realizing the importance of this skill at the bedside.

\section{Caregivers have no formal means of debriefing and relieving stress}

Stress and grief are generated during caregiver conflict, family-caregiver conflict, sudden death, death of a close friend or family, divorce, changes in jobs or any unexpected outcome. Because of this distress, caregivers in small groups frequently discuss patients and their problems in lunchrooms, hallways and elevators. This management of overpowering emotions can be misconstrued as unprofessional and derogatory to patients ${ }^{[5]}$.

In this particular case; laughter and humor relieved tension and allowed caregivers to continue their work. They knew that talking felt good. Laughter is a quick fix for a very burdensome problem and thus the practice is perpetuated. Humor may serve several important 'relief' functions in the clinical setting, especially in coping with stressful situations. True humor can be said to have therapeutic as well as critical function to help healthcare professionals cope with difficult patients, demanding workload, sleep deprivation and other job frustrations ${ }^{[6]}$. There are short term and long-term benefits to any type of stress reduction. In the short term, the caregiver is relieved of immediate anger and frustration mentally and physically. As a result, the patient is the recipient of more rational and concerned care. In the long-term burnout, is prevented or alleviated allowing for caregiver retention. 
Moral distress is a huge issue for health care organizations. It is defined as the reaction to a circumstance where "the right thing to do" is readily perceived, but caregivers are prevented from following their values because of external restraints. This condition was originally described among nurses, but empirically occurs in many dimensions of healthcare ${ }^{[7]}$. It is a systems ethics issue, which spills over into the daily assignments of caregivers from the nurse aide to the attending physician, to the harried administrator, sapping the energy required for the care of the critically ill.

How are providers to cope in the day-to-day struggles of hospital work, particularly when dealing with overpowering emotions? According to the Ethics Work Group of FYO4 in their work summary on "Moral Distress" describes a series of steps to help caregivers recognize the effect on them. The four steps include asking themselves whether they are stressed or not? Caregivers affirm their distress and validate feelings and perceptions with others. Thirdly, they are urged to identify the sources of their distress. Lastly, they must personally and professionally take action. Action taken will depend on the person and situations encountered. Mitigation of stress is another reason continuing education is emphasized in most all professions. Reflecting on actions and situations can bring clarity and understanding to stressful issues that help to deal with future chaos. Lastly, all healthcare providers from the bedside to the boardroom need time set aside to express their frustrations, grief, losses and loneliness. Finding an opportunity to do this remains the continual quest ${ }^{[8]}$.

\section{Conclusions}

In summary, a case study was presented regarding a middle-aged recalcitrant homeless man who experienced severe trauma and survived despite his lack of cooperation with the medical regimen. Lessons learned are a culmination of ideas gleamed from multiple discussions with caregivers and research into similar situations. It is important to realize that disruptive patients do have rights and just because they interfere with the health care teams usual, routine does not permit team members to ignore the patient.

Trauma patients are typically evaluated in the emergency department \{ED\} and the physicians have an excellent opportunity to assess and document the patient's decision-making capacity. This simple evaluation is usually not documented, but should be in every history and physical examination. Just writing, "awake, alert, and oriented to time, place, and person" is not adequate to assess decision-making capacity. The question is, "Does this patient understand the severity of his or her condition?” The caring team needs this information up front to actively engage the patient in his or her own treatment plan. If the patient is incapacitated, a spokesperson should be immediately identified either in the hospital or through local government agencies.

New members of a nursing unit or treating team should during orientation, demonstrate their skills in evaluating capacity by using and documenting the components of decision-making capacity and informed consent process. This specific education would make a valuable in-service topic for quality improvement purposes.

As soon as the treating team identifies a complex patient, the multidisciplinary team needs to be mobilized and become knowledgeable about the care plan. Then as problems arise, they can be reconvened to assist in analyzing the problems. Personal distress elicited by the extremes of behavior from such complex patients would, thus be mitigated or prevented. The group process would allow for debriefing of stressful events and circumstances and therefore be a more ethical outlet for anxiety rather than inappropriate humor.

It has been the authors' intent to convey the ethical dilemmas of Mr. D's experience within a thoughtful and retrospective framework. We recognize the difficulties of delivering care to a person in the midst of confusion and overwhelming concern for saving a life. The overall impact on the healthcare team was analyzed. The impact of caring for this man has left a lasting impression on those who remember him.

Ideally, it would be helpful under similar circumstances to embrace and integrate these concepts and practices into daily clinical practice and then measure their effectiveness prospectively. 


\section{References}

[1] Jonsen A R, Siegler W, Winslade, W J. Clinical Ethics: A Practical Approach To Ethical Decisions In Clinical Medicine 6th Ed. New York: McGraw-Hill Medical Publishing Division. 2006; 88-92.

[2] Reeves RR, Douglas SP, Garner RT, Reynolds MD. The Individual Right of the Difficult Patient. \{Case Study/ Commentary\} The Hastings Center Report. 2007; 37: 13-15. http://dx.doi.org/10.1353/hcr.2007.0032

[3] Fletcher JC, Spencer EM, Lombardo PA. Fletcher's Introduction to Clinical Ethics 3rd Ed. Hagerstown, MD: University Publishing Group, 2005, 11.

[4] ALM. http://www.law.com (2 January 2008, date last accessed).

[5] Aultman JM. When Humor in the Hospital is no Laughing Matter. JCE. 2009; 20(3): 227-234.

[6] Critchley S. On Humor. London: Routledge, 2002, 15.

[7] Burkhardt MA, Nathaniel AK. Ethical Issues in Contemporary Nursing 3rd Ed. Clifton Park, New York: Thomson, Delmar Learning Center, 2008, 91.

[8] Ethics Work Group of FYO4. The 4 A’s to Rise Above Moral Distress. 2008. http://www.aacn.org/wd/practice/docs/4as_to_rise_above_moral_distress.pdf 